\title{
SUPERANDO O FALICISMO: SOFRIMENTO MATERNO NA PSICANÁLISE DE CRIANÇAS
}

\author{
Henriqueta Lúcia Arcoverde de Melo* \\ Fernando Cezar Bezerra de Andrade ${ }^{\#}$ \\ Hélida Magalhães da Costa Limađ
}

\begin{abstract}
RESUMO. Interpreta-se, no contexto da psicanálise de uma criança psicótica, o sofrimento materno e suas implicações nos destinos do tratamento. $\mathrm{O}$ sofrimento parental interfere negativamente quando compele à repetição fantasmática de traumatismos cujas mensagens, uma vez intrometidas, não são elaboradas pelos pais. Como demonstra o caso clínico, o falicismo materno e a foraclusão da função paterna não necessariamente estão presentes na geração da psicose. Longe de ser falo, originalmente ao paciente foi atribuído o lugar de substituto de um objeto odiado numa cena traumática vivida na infância materna, responsável pela intromissão de mensagens sexuais em torno de experiências de nascimento e morte, revividas fantasmaticamente no contexto da análise de seu filho.
\end{abstract}

Palavras-chave: Psicanálise da criança; relações pais-criança; sofrimento.

\section{BEYOND PHALLICISM: MATERNAL SUFFERING IN CHILD PSYCHOANALYSIS}

\begin{abstract}
The article interprets maternal suffering and its implications on a psychotic child's psychoanalysis. Parental suffering interferes with a child's treatment when it induces the repetition of fantasies generated in traumas whose messages, once intruded, were not worked through by the parents. As the clinical case demonstrates, the mother's phallicism and the foreclosure of the paternal function are not necessarily present in the origins of the psychosis. Far from being his mother's phallus, the boy received a role to replace a hated object in a traumatic scene lived precociously by his mother, during her childhood, when she received intrusive sexual messages related to birth and death, relived imaginarily by her during the boy's psychoanalysis.
\end{abstract}

Key words: Child psychoanalysis; parent-child relations; suffering.

\section{SUPERANDO EL FALICISMO: SUFRIMIENTO MATERNO EN EL PSICOANÁLISIS DE NIÑOS}

RESUMEN. Se interpreta, en el contexto del psicoanálisis de un niño psicótico, el sufrimiento materno y sus implicaciones en los objetivos del tratamiento. El sufrimiento parental interfiere negativamente cuando obliga a la repetición fantasmática de traumatismos cuyos mensajes, una vez entrometidos, no han sido procesados por los padres. Como demuestra el caso clínico, el falicismo materno y la foraclusión de la función paterna no están necesariamente presentes en la generación de la psicosis. Originalmente al paciente le fue atribuido el lugar de sustituto de un objeto odiado en una escena traumática vivida en la infancia materna, responsable por la intromisión de mensajes sexuales acerca de experiencias de nacimiento y muerte, revividas fantasmáticamente en el contexto del análisis de su hijo.

Palabras-clave: Psicoanálisis del niño; relaciones padres-niños; sufrimiento.

Mestra em Psicologia (Psicologia Social) pela Universidade Federal da Paraíba. Professora do UNIPE - Centro Universitário de Ensino. Psicanalista da Sociedade Psicanalítica da Paraíba.

\# Doutor em Educação pela Universidade Federal da Paraíba. Professor do Departamento de Fundamentação da Educação-Centro de Educação da Universidade Federal da Paraíba. Psicanalista da Sociedade Psicanalítica da Paraíba.

II Mestra em Psicologia (Psicologia Social) pela Universidade Federal da Paraíba. Mestra em Psicologia Clínica, Psicopatologia e Psicanálise pela Université René Descartes - Paris V - Sorbonne. Professora do Departamento de Psicologia da Universidade Federal da Paraíba. Psicanalista da Sociedade Psicanalítica da Paraíba. 
A especificidade da Psicanálise consiste no seu método e na situação analítica, cuja imbricação ordena à teoria que sirva à clínica. Elaborações teóricas verdadeiras encontram correspondência na prática psicanalítica e do processo de cura elabora-se a teoria (Laplanche, 1992). Estes princípios podem ser traídos, porém, se a teoria que orienta o profissional no tratamento for rigidamente pré-concebida: há o risco de perder-se a atenção flutuante, para servir a um paradigma teórico exclusivista. A escuta profissional pode até deformar o conteúdo provindo do paciente, fazendo do analista um hermeneuta a serviço do recalque (Laplanche, 1995).

Isso é ainda mais verdadeiro na clínica com crianças, já que nela estão implicadas dificuldades a mais. Uma delas é a do terceiro-interveniente, que pode ameaçar a situação analítica - constituída pelo contexto da transferência e do enigma recriado pela situação antropológica fundamental (Laplanche, 1993) -, com suas exigências e objetivos. Isso contribui para acentuar eventuais contágios da escuta analítica de crianças - por vezes extremamente problemática em razão da interferência dos pais, cujos desejos podem opor resistências ao progresso da análise de seus filhos. Se os objetivos da criança guiam o trabalho, o processo é favorecido. Do contrário, "que esses objetivos estejam selados mediante um pacto que vincule a análise à demanda, à expectativa, ou ao controle de um terceiro, é dispor de saída as condições de uma resistência insuperável" (Laplanche, 1993, p.141).

Porém, sobretudo no caso de crianças pequenas ou psicóticas, como, senão no discurso dos pais, é possível ouvir fragmentos da história que interferem no processo de subjetivação do filho? $O$ trabalho analítico com a criança implica, para o diagnóstico e para o tratamento, na escuta do discurso parental. A fala dos pais revela teorizações, preocupações, fantasias, desejos e temores acerca das dificuldades apresentadas pelo filho, que permeiam a relação com o pequeno paciente.

Assim, é preciso ouvir a criança e seus pais através de uma escuta que, apoiada num modelo teórico aberto à expressão dos enigmas do paciente e de seus familiares no jogo transferencial, evite reduzir o entendimento do caso à pressuposição duma categoria clínica, cujas características, etiologia e prognóstico já seriam presumidas segundo um modelo estruturalista. Esse modelo, mesmo útil por organizar e simplificar a variedade fenomenológica em estruturas mais gerais (Dor, 1992), pode contribuir para uma interpretação reducionista, centrada em fórmulas sem alternativas ao pensamento.

Quando, por exemplo, adota-se a tese do falicismo materno, acompanhado da foraclusão da função paterna, para explicar a psicose pela "foraclusão do Nome-do-Pai no lugar do Outro, e no fracasso da metáfora paterna" (Lacan, 1998, p. 582), no contexto de uma teoria centrada na linguagem e em seus efeitos sobre o psiquismo, o sofrimento materno é reconhecido como sinal de um arranjo que, no fundo, denuncia o lugar fálico atribuído à criança; é, pois, um preço secundário a ser pago pela completude imaginária da mãe, que mantém a dualidade com sua criança.

Por outro lado, na perspectiva da Teoria da Sedução Generalizada (doravante TSG), o sofrimento parental indica a presença do ataque pulsional ao ego que não conseguiu traduzir mensagens enigmáticas no caso da psicose, mensagens intrusivas (Laplanche, 2008a). Na psicanálise de crianças, esse sofrimento permite inferir que o sintoma infantil sofre os efeitos do fracasso da tradução de enigmas parentais - não só pela criança, que não tem os dispositivos necessários ao processamento da mensagem sexual, mas, provavelmente, sobretudo pelo tipo de mensagem implantada ou encravada (Laplanche, 2007) - e, em razão dela, pela solução sintomática sempre deficitária que os pais dão àquela mensagem. Assim, o falicismo é apenas um - não o único - dos arranjos psíquicos que buscam dar resposta aos enigmas parentais mais intrusivos, não sendo o último nível de explicação para a psicose infantil.

O caso clínico, a seguir apresentado, ilustra essas considerações. Seu relato é feito em primeira pessoa, pois o caso e o registro da discussão com sua analista, em contexto de supervisão, envolveram diretamente apenas a primeira autora deste artigo. Em seguida, apreciamos os fragmentos registrados à luz da hipótese segundo a qual é necessário atentar para o sofrimento parental, pois é capaz de influir decisivamente os destinos da análise de crianças, por ser efeito de falhas na tradução de mensagens enigmáticas. Como corolário dessa hipótese, afirmamos que explicar a psicose restritivamente, apelando rígida e exclusivamente para um modelo teórico - no caso, o do falicismo materno e da foraclusão da função paterna - é incorrer em reducionismo teórico, pelo qual se perde a chance de atentar para a originalidade de cada tentativa de tradução dos enigmas parentais - inclusive para o que revela o fracasso da tentativa, que pode assumir configurações distintas daquela em que a criança é o falo da mãe.

No recorte da interrupção dramática da psicanálise de Pedro (pseudônimo de um menino psicótico de 9 anos) por Ana (pseudônimo da mãe da criança), tentamos entender o ocorrido com ela e Iva (pseudônimo da analista da criança). 


\section{FRAGMENTOS DO INÍCIO E DO FINAL DO CASO: A ECLOSÃO DA SITUAÇÃO TRAUMÁTICA}

Sem disponibilidade de horário, em meados dos anos 90, atendi a uma solicitação de consulta para Pedro, após muita insistência materna. Realizei duas entrevistas com Ana, informando-lhe, de saída, que iria encaminhar o caso para uma colega. De acordo com a sintomatologia descrita pela mãe, parecia tratarse de um caso de psicose infantil, o que exigiria maior número de sessões com a criança e seus pais. A mãe, relutando e dizendo ter gostado muito de mim, aceitou a indicação.

Durante dez meses de análise tudo parecia transcorrer sem problemas. A mãe, embora solicitasse a Iva muitas sessões para si própria e tentasse evitar a ida de João (pseudônimo do ex-marido, pai de Pedro) às sessões, parecia satisfeita com os progressos do filho. Entretanto, na volta das férias, Ana, extremamente perturbada, invadiu meu consultório, com urgência para falar comigo. Atendi-a e, ao longo da sessão, apesar da forte transferência negativa instalada na relação com Iva, referia melhoras do Pedro: ainda assim, estava decidida a encerrar a análise. Falou que tudo parecia transcorrer bem, mas, desde o retorno das férias não tinha conseguido levá-lo às sessões. Extremamente ambivalente, falava dos progressos do menino e, ao mesmo tempo, desconfiava dos sentimentos que a analista nutria por ela: "Ela [Iva] me odeia! Vai fazer muito mal a Pedro! Tenho medo, não confio mais nela! Só confio em você!!"

Firmemente, afirmou que não levaria mais a criança às sessões, nem mesmo para encerrar o processo, embora ele já recomeçasse a apresentar perturbações na linguagem e comportamentos autodestrutivos. Com efeito, a retomada de alguns sintomas parecia ser a única forma de o garoto falar sobre o sofrimento materno, que contaminava seu processo analítico.

Foram vãos os esforços no sentido de fazê-la iniciar a própria análise, de procurar Iva e falar do que sentia. Pontuei a gravidade da problemática de Pedro, as melhoras obtidas no tratamento da criança e as contradições presentes no seu discurso. Afinal, Ana aceitou a realização de duas sessões de Pedro com Iva, para o encerramento do processo, desde que acontecessem na sua presença. E assim a análise foi encerrada.

Algum tempo depois, Iva, na tentativa de elaborar o desfecho dramático desse caso, procurou-me em supervisão. Tivemos alguns encontros e nossa discussão iniciou-se a partir do registro da última sessão realizada com a mãe antes das férias. Nessa sessão, Ana dizia-se triste pela proximidade do Natal. Parecendo angustiada, falava que não tinhas boas recordações dessa época: “... Nunca gostei dessas festas, muito consumismo, dificuldades em reunir a família e pouco sentido religioso do Natal", acrescentou. Na saída da sessão, de forma inabitual, Ana apertou a mão de Iva, desejou-lhe um bom Natal e boas férias. A analista, respondendo aos votos de Ana, reafirmou o dia e hora da sessão do retorno de Pedro. E, aos poucos, retomamos os registros das sessões realizadas: 73 sessões com a criança, 17 com a mãe, quatro com o pai.

\section{TENTATIVAS (FRACASSADAS) DE TRADUÇÃO: OS IMPASSES DE UM SOFRIMENTO NÃO- ELABORADO}

Sabe-se que, numa psicanálise de criança, o desejo parental de interromper o processo analítico do(a) filho(a), mesmo com evolução satisfatória, não surpreende. A resistência parental à cura da criança, associada a alguma angústia - e, portanto, ao sofrimento parental diante dos riscos de ver-se privado de ganhos secundários dos sintomas que levaram à análise - é inerente a todo processo de análise. O que faz a especificidade do caso de Pedro? Precisamente, a irrupção dramática da transferência negativa materna, recaindo sobre a analista do menino, combinada à ambivalência do desejo materno: interromper a análise do filho, que evoluía positivamente, e, voltando para a analista do primeiro contato, a quem efetivamente procurara, tentar manter a análise. Impressionou a força do desejo de Ana, irrompendo com tanta destrutividade! "Não confio mais nela [Iva], ela me odeia, pode prejudicar Pedro”, dizia emocionada.

Tomamos como ponto de partida a aparência traumática do que se revestiu o desfecho do processo. Ora, a noção de trauma remete-nos ao esquema freudiano da sedução (Freud, 1896/1986). Uma característica desse esquema, posta em relevo por Laplanche e Pontalis (1991), refere-se à temporalidade que lhe é peculiar. Uma temporalidade que permite caracterizar o tempo psicanalítico por excelência, o tempo do après-coup. Outro elemento importante é o caráter irruptivo, excessivo que envolve a cena, para Freud sempre de natureza sexual. Para a TSG, a irrupção é uma possibilidade permanente nas relações entre pulsões e o eu, que se vê atacado justamente naquele flanco mais fraco e, para defender-se, recorre a mecanismos como o recalque. Nem sempre, porém, é possível recalcar todo o conteúdo ameaçador, uma vez que ele provém, com frequência, de mensagens enigmáticas implantadas ou intrusivas - estas últimas 
oferecendo a maior dificuldade possível às traduções (Laplanche, 2008b).

Por essa perspectiva, a análise de Pedro constituiu-se num segundo tempo de um trauma para Ana, que procedia de uma família numerosa: era a penúltima filha de uma prole de sete filhos. Aos dois anos de idade sua mãe faleceu, em decorrência do parto do irmão caçula. Seu pai nunca refez sua vida amorosa. Sempre presente, mas silencioso e depressivo, encarregou a filha mais velha, ainda adolescente, da tarefa de cuidar dos irmãos. Ana falava de uma infância difícil, permeada de insegurança e solidão. "Minha irmã mais velha só tinha olhos para o caçula", dizia ela. Por muito tempo, "tinha ódio dele, até que Deus me ensinou o caminho o amor e do perdão", acrescenta. Gostava do pai, lembrado como trabalhador, dedicado à família, mas autoritário e pouco afetuoso.

A história de Ana impôs-lhe profundas carências e dolorosos sentimentos: a mãe passou rápido em sua vida. Aos dois anos, com a morte da mãe, achou-se inserida numa triangulação edípica problemática, na medida em que sua irmã mais velha, por determinação do pai, passou a ocupar, imaginariamente, o lugar da mãe junto aos irmãos e à rotina doméstica. A mãe dos filhos do pai fez-se também a irmã dos irmãos.

Porém, como esses dados biográficos ligaram-se aos movimentos transferenciais emergentes e violentamente intensificados, ao longo da análise de Pedro? O que houve com Ana? O que se repetiu na transferência? E na contratransferência?

Uma demanda materna foi reiteradamente expressa e ouvida, mas até então nunca entendida pela analista. Além das frequentes solicitações de entrevistas com a analista do filho, Ana repetia, com insistência, durante as sessões: "Você [Iva] não me compreende, não entende o que eu falo", possivelmente tentando expressar um desejo infantil nunca satisfeito e duplamente imperioso. No decorrer da análise, esse desejo travestia-se tanto na tentativa de ditar normas de condução da análise de Pedro, na curiosidade de saber o que se passava nas sessões realizadas com o filho e com o pai dele, quanto na tentativa de excluir o ex-marido do tratamento. "Você [Iva] está errada, não me compreende, Pedro não precisa de pai, ele tem a mim”, insistia Ana.

Para consolidar esse arranjo, a exclusão de João do processo, desejada por Ana, vinha ao encontro do desejo do próprio pai do menino. Parecendo impedido de ocupar a função paterna, estabelecia uma cumplicidade velada com Ana. Dizendo-se parecido com o próprio pai, o qual foi descrito como "um mero espectador na educação dos filhos”, limitou-se a comparecer às sessões quando convocado. Parecendo preso à imagem da mãe onipotente, afirmava com frequência: “A mãe é quem sabe, pois é quem cria”. Em sua redoma narcísica, não se envolvia nos cuidados de Pedro, a quem se referia como "o rapaz". Por vezes, perguntava a Iva: "O que o rapaz diz de mim?", o que mais evidenciava um autointeresse do que uma preocupação com o filho. Em termos de sofrimento, João parecia incólume.

Tudo parecia estar consumado: o jogo relacional mostrava mãe fálica, pai narcísico foracluído, filho psicótico. Como entender de outro modo? Sobretudo, o que seria possível fazer, considerando a fixidez das estruturas? Ora, mesmo que Iva não fosse lacaniana, sistematicamente fazia supervisão clínica com um analista simpatizante dessa teoria. Logo, por toda análise de Pedro, a escuta de Iva, impregnada das concepções estruturalistas acerca da psicose, concebia Ana como perversa, que ditava regras, negava o lugar de sujeito para o filho e excluía o terceiro da relação, por não aceitar a castração simbólica, perpetuando a relação dual típica do primeiro tempo do Édipo lacaniano e promovendo, assim, a foraclusão do Nome-do-Pai. Numa primeira escuta, era natural que uma exibição fálica da mãe de Pedro com a cumplicidade de um pai frágil e que não ocupava o seu lugar, tomassem conta da cena.

Contudo, a insistência nesse tipo de interpretação parecia favorecer a instalação de um diálogo de surdos. Iva não estava livre para ouvir o que havia para além do modelo teórico restritivamente adotado. Algo da ordem de uma demanda, de uma carência, de uma falta que se expressava ora sob a forma denegadora de um discurso fálico, ora como apelo desesperado: "Você não me compreende!" Vivências de desamparo, mensagens enigmáticas veiculadas ao longo dos primeiros cuidados, mas que, interpretadas por Iva apenas como falicismo materno, não atingiam o sofrimento de Ana e inviabilizaram tentativas maternas de destradução e tradução das mensagens enigmáticas (Laplanche, 2007, 2008b) do resultado do recalque.

Para Laplanche (1992, 1993), cabe à clínica promover a análise do recalque, de sorte a permitir que novas traduções refaçam o texto inicialmente produzido pela tradução constitutiva do inconsciente. Se o paciente é o primeiro hermeneuta de si próprio (Laplanche, 1995), não há como contar a própria história sem dificuldades. No campo da sexualidade infantil, recalcada e polimorfa, aliás, essa tradução será sempre marcada pelos restos de mensagens enigmáticas, que reclamam novas traduções a serem constantemente revistas - sendo esse, portanto, o trabalho da análise.

No caso da análise de Pedro, não só o menino, como sua mãe reclamava uma revisão, sem o saber. Iva, porém, tomada por fortes sentimentos em sua 
contratransferência, se sentia dividida entre a demanda imperiosa dos desejos infantis maternos e a necessidade também imperiosa de cuidar de Pedro. Instava Ana, em vão, a procurar uma análise. A sensação de desconforto acontecia com certa frequência. Embora Pedro evoluísse, Ana parecia não ser compreendida. Por vezes, sentia-se desamparada pela teoria, na condução do caso. Quanto mais analisava o caso à luz do falicismo materno, mais se exacerbava o sofrimento de Ana. Entretanto, Iva, prisioneira do esquema teórico de referência de seu supervisor, tendia a ver as dificuldades maternas como novas ilustrações clínicas da perversão de Ana.

Em outros momentos, sentia-se impotente para cuidar do caso. Talvez fosse difícil demais, complexo demais, para além da sua capacidade profissional. Também sentia raiva de Ana. Percebia-a extremamente exigente e invasora. Cobrava-lhe atenções em demasia às suas queixas e pedidos e tentava se colocar, todo tempo, no centro da cena. Sentia-se fracassado como analista, embora Pedro evoluísse bem. Repetidamente, sentia falta da colega analista que fizera as entrevistas iniciais. Pensava que sendo ela mais experiente poderia cuidar melhor desse caso.

\section{O APRÈS-COUP DO TRAUMA MATERNO: UM ENIGMA ATUALIZADO}

A análise da contratransferência colocou-nos na trilha de uma melhor compreensão. A partir de fragmentos da história de Ana, foi possível pensarmos em uma repetição que permitiu traçar um paralelo entre a vivência contratransferencial da analista de Pedro e o que, provavelmente, foi vivido pela irmã adolescente de Ana quando assumiu os cuidados dos irmãos. Pareceu-nos que, tal como a irmã adolescente, a analista de Pedro sentiu falta da colega que lhe encaminhou o caso - a mãe. Sentia-se só, insegura na condução da análise, embora orgulhosa do encaminhamento. Pensava que essa colega fora um tanto irresponsável, deveria ter sido ela, procurada primeiramente, quem deveria ter ficado com o difícil caso.

A analista/irmã, dividida entre cuidar de Pedro/o bebê e cuidar de Ana/a menina sem mãe, não conseguiu materná-la, só tinha olhos para o caçula. Pedro/o bebê ocupava um espaço muito grande nos seus cuidados, tamanha era a sua fragilidade! Então, a analista exigia de Ana/a menina que a ajudasse nessa tarefa, que também dividisse com ela os cuidados de Pedro. A demanda de cuidados feita por Ana/a menina estava acima de suas forças, de seu entendimento. Maternar Pedro/o bebê já se constituía numa tarefa grande demais para ela. Ambivalente, a analista/irmã percebia a fragilidade de Ana, mas não conseguia ouvi-la. Possivelmente, a raiva da analista/irmã, dirigida a Ana/à menina, era expressa de forma velada, pelas interpretações e exigências que fazia a Ana ao longo da análise de Pedro, o que aparecia no discurso de Ana: "Ela [Iva] me odeia!".

Ana, por sua vez, vivendo a análise do filho como repetição de fragmentos de sua história, permaneceu encerrada no seu mundo fantasmático infantil. Eram recorrentes suas manifestações de raiva, inveja e ciúmes, seja em relação a Pedro ou a Iva, seja ainda em relação a João, sempre antecedidas por muita angústia. Perguntava, de forma assertiva e com certa insistência: "O que acontece entre você e Pedro durante as sessões? O que se passa nas sessões realizadas com João?".

A frustração dessa demanda infantil e a leitura teórica naquela circunstância adotada por Iva como uma camisa de força determinavam uma escuta das estruturas envolvidas na problemática de Pedro, intensificando a resistência e a eclosão da transferência negativa materna. Foi então que Ana buscou a analista dos primeiros contatos - figura idealizada da mãe perdida, investida duma feição especial. "Com você seria diferente", disse-lhe Ana, entre lágrimas, após a interrupção da análise do menino, reclamando inconscientemente por seu lugar de filha junto à mãe morta.

A escuta e a interpretação de Iva, centradas na trama do desejo fálico da mãe de Pedro, não conseguiam distinguir o desejo de Ana como filha e irmã. Este era o cerne do enigma com que Ana estava às voltas, no après-coup traumático definido, inicialmente, pelo nascimento de Pedro - primeiro filho, tornado psicótico por ter sido situado no lugar do tio materno, com quem Ana competia e cuja morte desejou diversas vezes; e, mais tarde, pela triangulação Iva-Pedro-primeira analista procurada por Ana. Supomos que o nascimento do filho possivelmente mobilizou pensamentos como: "assim como meu irmão matou minha mãe, esse meu filho matar-me-á, se eu não o matar antes: ou ele, ou eu". E inferimos que a análise de Pedro permitiu a Ana atuar, em resposta a mensagens dificílimas de traduzir, por uma menina de dois anos, pensamentos como: "Odeio a irmã que me preteriu e a mãe que me abandonou, ambas em favor desse menino!". No lugar de objeto transferencial, Pedro resumia - como filho-irmão de Ana, recusado pela primeira analista e aceito por Iva os dois lados do sofrimento materno, organizado sem uma tradução mais desejável para os enigmas sexuais que, por fim, tornaram-se também narcísicos ("ou ele, ou eu"). João, distante e frio como o pai de Ana, consagrava a solução repetitiva e sintomática. 
Foi somente com a interrupção abrupta do caso e as primeiras tentativas de elaboração deste, em outra supervisão, que Iva pôde reconhecer que, para além da rigidez estrutural, havia que ser considerado o sofrimento materno, no recorte da história de Ana. Paralelamente, as interpretações dirigidas à mãe com ênfase na problemática de castração materna parecem ter estado a serviço da intensificação das mensagens intrusivas, ao dificultarem o movimento de destradução e novas tentativas de tradução do material não-inscrito que emergiu num momento da análise do Pedro.

\section{CONSIDERAÇÕES FINAIS}

Do caso de Pedro, aprendemos que o sofrimento parental deve sempre ser levado em conta na psicanálise de crianças, tanto por interferir, muitas vezes, como resistência, quanto porque pode representar dificuldades parentais em traduzir mensagens enigmáticas - aumentando a probabilidade de que a criança receba mensagens intrusivas, de tradução muito custosa, o que a submete a patologias mais graves, como a psicose. Para estas, de nada adianta recorrer, de forma reducionista, a uma explicação estruturalista, que deixa passar as sutilezas dos arranjos definidos por mensagens enigmáticas, sempre particulares, originais - em razão do caráter pessoal da metábole (Laplanche, 1992).

A sequência involuntária de eventos desse caso e a condução da análise por Iva constituíram-se em agentes traumáticos para Ana, cujas vivências infantis - prenhez de mensagens comprometidas com o inconsciente dos adultos envolvidos em seus cuidados, a partir da gravidez da mãe e o nascimento do irmão, seguido da morte materna - permaneceram encravados no seu inconsciente, um corpo estranho interno, fixado sem possibilidades de obtenção de êxito nas tentativas de tradução (Laplanche, 2008a). Assim, a proximidade da situação externa - análise de Pedro - e os primórdios da história de Ana estiveram na base das manifestações repetitivas observadas nos movimentos transferenciais. A recusa da primeira analista em atendê-la, a dificuldade da segunda analista em ouvila, a interrupção das férias parecem ter atualizado o trauma experimentado por Ana em tenra idade. Possivelmente, o processo analítico recolocou fragmentos de cenas extremamente dolorosas como tentativas de transcrições das mensagens enigmáticas não-metabolizadas, porque intrometidas.

\section{REFERÊNCIAS}

Dor, J. (1992). A noção de estrutura. In J. Dor. (Carlos Eduardo Reis, Trad.) Introdução à leitura de Lacan (pp.22-25). (3a ed.). Porto Alegre: Artes Médicas.

Freud, S. (1986). A etiologia da histeria. In J. Strachey (Ed. e J. Salomão, Trad.), Edição Standard Brasileira das obras psicológicas completas de Sigmund Freud (2a ed.). (Vol. 3, pp.177-206). Rio de Janeiro: Imago. (Original publicado em 1896).

Lacan, J. (1998). De uma questão preliminar a todo tratamento possível da psicose (Vera Ribeiro, Trad.). In J. Lacan, Escritos (pp.537-590). Rio de Janeiro: Jorge Zahar Editor.

Laplanche, J. (1992). Novos fundamentos para a psicanálise. (Cláudia Berliner, Trad.). São Paulo: Martins Fontes. (Original publicado em 1987).

Laplanche, J. (1993). A tina. A transcendência da transferência. (Paulo Neves, Trad.). São Paulo: Martins Fontes. (Original publicado em 1987).

Laplanche, J. (1995). A psicanálise como antihermenêutica (Luís Maia, Trad.). Psicanalítica, n. 3, p.71-86.

Laplanche, J. (2007). Trois acceptions du mot «inconscient» dans le cadre de la Théorie de la Séduction Généralisée. In J. Laplanche. Sexual (pp.195-214). Paris: PUF. (Original publicado em 2003).

Laplanche, J. (2008a). Le traitement psychanalytique des états psychotiques. In J. Laplanche. La révolution copernicienne inachevée -1967-1992 (pp.125-129). Paris: PUF. (Original publicado em 1972).

Laplanche, J. (2008b). Implantation, intromission. In J. Laplanche. La révolution copernicienne inachevée 1967-1992 (pp.355-358) Paris: PUF. (Original publicado em 1992).

Laplanche, J., \& Pontalis, J. B. (1991). Vocabulário da psicanálise. (Pedro Tamen, Trad.) (11a ed.). São Paulo: Martins Fontes.
Endereço para correspondência:
Henriqueta Lúcia Arcoverde de Melo. Praça João Brasil Mesquita, 19, Miramar, CEP 58043060, João Pessoa-Pb, Brasil. E-mail: henriquetaarcoverdemelo@ hotmail.com. 